Synthesis, part of a Special Feature on Implementing Participatory Water Management: Recent Advances in Theory, Practice and Evaluation

\title{
A Framework for Clarifying “Participation" in Participatory Research to Prevent its Rejection for the Wrong Reasons
}

\author{
Olivier Barreteau $^{1}, \underline{\text { Pieter W. G. Bots }}^{2}$, and $\underline{\text { Katherine A. Daniell }}^{3}$
}

\begin{abstract}
Participatory research relies on stakeholder inputs to obtain its acclaimed benefits of improved social relevance, validity, and actionability of research outcomes. We focus here on participatory research in the context of natural resource management. Participants' acceptance of participatory research processes is key to their implementation. Our first assumption is that this positive view and acceptance of participation in research processes is a public good for the whole participatory research community. We also assume that the diversity of participatory forms of research is rarely considered by potential participants when they make their decisions about whether or not to participate in a proposed process. We specifically address how to avoid stakeholders' reluctance to be involved in participatory research projects based on disillusion with past experiences. We argue that the disappointment experienced by stakeholders and other participants (i.e., researchers and policy makers) can be avoided by being upfront and precise about how "participation" will be implemented, and what kind of involvement is expected from participants. Such a collective effort from the research community can also clarify the variety of possible implementations for potential participants. Building on earlier efforts to characterize and categorize the diversity of participatory research approaches, we develop a conceptual analytic procedural framework to make participants' roles explicit in the implementation of different participatory research processes. This framework consists of three facets: (1) the flows of information among participants and the control over these flows for each step in a process, i.e., who will be expected to produce information, who will use this information, and who will receive the results; (2) the timing of the involvement of participants in the different steps of the research process, and the framing power that is associated with each process step; and (3) the organization of communication among participants for each information flow, i.e., in what configuration (bilaterally or as a group, mediated or face to face) the interactions among researchers, stakeholders, and policy makers will take place. This framework can accommodate a wide variety of research methods, and highlights exactly how participants are involved in research processes. We are prescriptive in dealing with the need to be procedurally explicit when engaging in participatory research. We anticipate that using this framework will lead to more thoughtful acceptances or refusals to participate in proposed research processes. Our framework is based on various experiences with participatory research. It is intended to be used from the very beginning of a participatory research process as a conceptual guide for researchers. We suggest a protocol to transform it into more practical guidelines for communicating about upcoming participatory research processes. The leader of such processes should propose at each key stage an explicit, yet adaptive, plan for the following stages. This plan should also specify in what ways participants will be involved, and how the plan itself can be questioned and revised.
\end{abstract}

Key Words: framing; information flow; participatory research; water management 


\section{INTRODUCTION}

Communism has been rejected on account of flaws observed in its various implementations, without thorough discussion about how remote these implementations are from the sociopolitical theory on which they were inspired (Heywood 2003). Although it stems from radically different philosophical roots, participation is also, and increasingly, marketed as a way to establish more justice in the world and is presented as a universal value. Participation has become a label that is generously self-attributed, and its implementation is becoming widespread in an expanding range of domains around the world. In natural resources management (NRM), participation is heralded as a way of building the adaptive capacity and social learning required for the development and maintenance of resilient and sustainable socioecological systems (Pahl-Wostl et al. 2007). Will it live up to these expectations? Or will participation meet the same fate as communism, because of the disqualification of some of its specific implementations? Will people invited to participate become skeptical after experiencing participatory processes that did not let them "participate" in the way they expected?

The rapidly expanding literature on participatory approaches in various domains (Cleaver 1999, Blumenthal and Jannink 2000, van den Hove 2000, Driessen et al. 2001, Forssén and Haho 2001, Glendinning et al. 2001, Hare et al. 2003, Kujala 2003, Pereira et al. 2003, Mostert 2006) shows a tremendous diversity in purpose, process design, and implementation (von Korff et al. 2010). The academic debate typically focuses on what to do or analyze (Walker et al. 2002), who to involve (Rowe and Frewer 2000, Fung 2006), or how to adapt to the local context (Kujala 2003, Miettinen and Virkkunen 2005, d'Aquino 2009). As this diversity spreads to the practice of participation, always with the same "participatory" label, the risk of confusion increases. When participants do not know what to expect in a "participatory process," they are prone to disappointment, an emotion that is experienced "in response to unexpected negative events that were caused by uncontrollable circumstances, or by another person. [...] Disappointment results in feeling powerless and inactive" (Zeelenberg et al. 2000). This implies that people who are disappointed while participating in a process will be disinclined to continue or to participate in some future process. Barbier (2005) has observed such cases of ironical disengagement.

Here, we focus in particular on participation in scientific research. In this field, expectations for participatory research include the creation of more policy-relevant research outcomes, easier access to information, or better diffusion of results (Martin and Sherington 1997, Barnett 2004, Stringer et al. 2006). Already in 1995, Cornwall and Jewkes remarked that participation was becoming a cliché, and a concept that could be mobilized "...not only to enable local people to seek their own solutions according to their priorities, but also to secure funding, to co-opt local people into the agendas of others or to justify short-cut research within a topdown process." They also point out the following:

...[T]he key element of participatory research lies not in methods but in the attitudes of researchers. The key difference between participatory and other research methodologies lies in the location of power in the various stages of the research process. [...] [T]he single most striking difference between participatory and conventional methodologies [...] lies less in the theories that inform these methodological frameworks or even in the methods they use, but in who defines research problems and who analyses, generates, represents, owns and acts on, the information that is sought.

Hence, when explaining the purpose and content of a potential participatory research project to people, and what their "participation" in it entails, special attention should be given to who has control over the research process and to how its outcomes are disseminated.

The diversity in the design and implementation processes of participatory research is as large as that of other kinds of participatory decision making. Cornwall and Jewkes (1995) point out a conceptual blurring of the concept of participation and call for a greater discipline in the qualification of the meaning of participatory research. This is not a plea for uniformity. The diversity in design and implementation is functional: it allows adaptation and flexibility (Stringer et al. 2006). Practitioners know all too well that for participatory processes, "the devil is in the details," in the sense that outcomes largely depend on process (Beierle and 
Cayford 2002). This high sensitivity to context in participatory practice (Martin and Sherington 1997, Miettinen and Virkkunen 2005) also means that it is exceedingly difficult to extrapolate from one case to another. However, people who are called to participate commonly do extrapolate from their own experiences and the accounts of others' experiences.

We consider the reputation of participatory research as a type of public good for the participatory research-related scientific community, for it is difficult to exclude anybody from using it and there is no real subtractability (Ostrom et al. 1994), even though each reference to a "participatory research process" will affect the reputation of this type of research. Any researcher who invites people to take part in a participatory research process will contribute positively to this public good if these participants are happy with the actual process and the outcomes, or will contribute negatively to it if they are not.

There are no rules yet for managing this public good. Unlike the appellation of wine regions in France, the designation of "participatory" is not protected by means of established specifications and an institution that can enforce them. We address this problem by taking a prescriptive stance, urging practitioners of participatory research to clarify to potential participants what type of participatory research process they propose to implement. Our conviction that such clarification is the best strategy to sustain the reputation of participatory research as a public good is based on two main assumptions: (1) Any attempt to define what is, or what is not, participatory research will be in vain because of the already existing diversity of definitions and the absence of any authority to enforce adherence to one definition. (2) Procedural transparency through a fine-grained characterization of participatory research processes enables participants to differentiate between various implementations; to adapt their expectations about their involvement in the process and what the process will bring to them; and to improve their assessment of the process and their ability to share these evaluations in a debriefing stage. In other words, we expect that the informed description of past implementations of participatory research processes will provide support for dialog on the implementation of new participatory processes.

We must emphasize that although transparency is an important and recurring topic in the participation literature, we take a particular viewpoint here. We do not call for transparency because it is considered to be one of the attributes of effective participation (Rowe and Frewer 2000) or a condition for good research (Fossey et al. 2002), but first and foremost to better inform the decision of potential participants to accept or refuse to participate in proposed research processes. This should help prevent refusal to participate based on the wrong reasons, notably false expectations or prejudices resulting from faulty assessments of participatory research processes. When researcher $R$ proposes "a participatory approach," the intended participant $T$ may understand this to mean $X$ and reject it out of hand, because $T$ does not like $X$, whereas $R$ actually intends to do $Y$, which $T$ might have liked. Conversely, after a bad experience with participatory research of type $X$ that was not expressly explained to be $X, T$ will likely assess any participatory research as bad, and develop or ingrain a prejudice against the whole category, ignoring or being incapable of distinguishing the differences between $X, Y$, or other types of participatory processes. Clarifying "participation" can prevent both types of faulty reasons from influencing participants' decisions. As a side effect, achieving this procedural transparency will also improve researchers' learning about the practice of participatory research.

Thus, our aim here is to provide an analytic procedural framework to specify and qualify participatory research processes in detail. This framework should help researchers to:

- make explicit what may be expected from people when they engage in a specific participatory research process implementation;

- decrease the potential for after-the-fact frustration of participants; and

- collect empirical data for fine-grained analysis and comparison.

We build upon earlier work on the categorization of participatory research. Biggs (1989) distinguishes four modes of participation in research: "contractual," "consultative," "collaborative," and "collegiate," where control over the research process gradually shifts from scientists to local people. These modes are quite close to the often cited citizen-participation levels that Arnstein (1969) proposed for participatory urban redevelopment processes. Cornwall and Jewkes (1995) see these 
modes as points on a scale from "shallow" to "deep" participation and contrast this "depth" dimension with the "scope" dimension on a scale from "narrow" participation, i.e., few participants, to "broad" participation, i.e., many participants. They emphasize that the depth and scope of participation may fluctuate in the course of the process, depending on context and objectives.

More recently, Probst and Hagmann (2003) have generalized Biggs' typology and made it more symmetrical. Their scale progresses from all power residing with a single actor to a distribution of power over all the participating stakeholders. In this way, the single actor may be the researcher, as it is in Biggs' typology, but it may also be a policy maker or a specific stakeholder group. This generalization of Biggs' four participation modes is presented in Table 1.

We advance the line of thought set out by Biggs (1989), Cornwall and Jewkes (1995), and Probst and Hagmann (2003) by elaborating three complementary facets of a participatory research process that these authors mention but do not develop: (1) participants' control over the flow of information; (2) changes in the actors' modes of participation over time; and (3) management of participants' heterogeneity in the participatory process.

We illustrate our framework by referring to case studies from two NRM research projects, AquaStress (http://www.aquastress.net/) and $\mathrm{Ne}$ Water (http://www.newater.info/), both funded under the European Union's Sixth Framework Program for Research and Development. Both projects had the explicit aim of involving stakeholders in research on issues related to water management. This Ecology and Society special feature details a number of elements of the participatory research case studies developed in these projects. These projects have put in place either a standard (NeWater) or protocol (AquaStress) for monitoring and evaluating participation (von Korff and Barreteau 2005) in terms of context, process, and outcomes (von Korff 2005). Nevertheless, experiences with AquaStress and NeWater show that implementations of stakeholder participation in research can differ significantly despite efforts to coordinate and standardize approaches across different case studies (Barreteau and von Korff 2007). The research objectives, the size and composition of groups of participants, the types of participants, and the structure of the interactions among researchers and participants were very diverse. This has inspired our framework design, but we must emphasize that the framework we propose has not been applied or tested in either project.

Below, we lay out the basis for our analytic framework by explaining an abstract model of participation in research processes and the key concepts this model provides. We then develop the three facets addressed in our framework, and discuss the issue of managing a dialog about participatory research processes, contributions to existing categories, and possibilities for using the framework in ongoing participatory research processes. Finally, we argue that to advance the state of the art, it is necessary to develop a format for a logbook of participatory research implementations that affords more precise tracking and systematic comparison, and we offer a number of suggestions for how the framework could be used in practice.

\section{METHODS}

Because the analytic framework we propose has been inspired by, but not tested in, empirical case studies, we focus on its "conceptual" validity. "Conceptual validity means that the theories and assumptions underlying the conceptual model are correct, or at least justifiable, and that the model representation of the problem or system, its structure, logic, mathematical, and causal relationships, are reasonable for the model's intended use" (Rykiel 1996). The intended use of our analytic framework is to clarify the differences among the many ways in which participatory NRM research can be implemented. It is not intended to predict the outcomes of different implementations. It should provide material for clarification before start up, and follow-up evaluation, of participatory research processes.

Our method relies upon a descriptive model of the general structure of participatory NRM research that brings to the fore the relevant dimensions on which implementations of such processes can differ. The literature on participatory research that we reviewed above mentions five such dimensions: (1) the actors involved in the process; (2) the flows of information; (3) the control actors exert over the process and the information; (4) the research methods that are used; and (5) time, given that the involvement and influence of actors often change as the process moves from one stage to the next. 
Table 1. Different participation modes in research and innovation processes (adapted from Probst and Hagmann 2003).

\begin{tabular}{ll} 
Participation mode & Characteristics in terms of actor involvement and control over the process \\
\hline Contractual & $\begin{array}{l}\text { One actor has sole decision-making power over most of the decisions taken in the process, and can be } \\
\text { considered the "owner" of this process. Other actors participate in activities defined by this "owner" } \\
\text { by being (formally or informally) "contracted" to provide services and support. }\end{array}$
\end{tabular}

Consultative $\quad$ Most of the key decisions are kept with one actor, but emphasis is put on consultation and gathering information from other actors, especially for identifying constraints and opportunities, priority setting, and/or evaluation.

Collaborative Different actors collaborate and are put on an equal footing, emphasizing links through an exchange of knowledge, different contributions, and a sharing of decision-making power during the process.

Collegiate

Different actors work together as colleagues or partners. "Ownership" and responsibility are equally distributed among the partners, and decisions are made by agreement or consensus among all actors.

To elaborate on these dimensions in a coherent framework, we start with a conceptual model of scientific research linked to a policy context. The right hand section of the diagram presented in Fig. 1 represents scientific research as a cyclic process that comprises: (1) formulating research questions; (2) selecting appropriate methods; (3) applying these methods to obtain results; and (4) reflecting on these results, typically leading to new research questions. The left hand section of the diagram represents the link between science and policy: scientific findings may inform policy decisions, and policy issues may prompt research questions.

We choose this particular representation for three reasons. First, it identifies the most crucial choices that are made in a research process: the policy issue that will be focused on, the research questions that will be addressed, the methods that will be used, and the results that will be taken into account. This links process to power, as these choices are linked to the question of which actors are involved in making them, and how much influence they can exert on the process. Second, the model is general: it does not assume any particular type of research question, method, or results. Finally, it represents the cyclic dynamic that is emphasized in many participatory, and/or action, research approaches (Lewin 1946, Bousquet et al. 1999, Goldspink 2002, Fischer et al. 2005, List 2006).

The research process can be further specified by considering the role of models in this process. Our focus on NRM brings these to the fore, as most studies in this domain use models, at least to tackle the issue of understanding resource dynamics. To remain general, we consider a model as any representation of a system that is stable enough to serve as the basis for a discussion about the system it represents. This might take many forms, such as mathematical equations, computer code, diagrams, games, or any combination of these. We distinguish among these four roles:

1. "Model" is defined by "method." A research method may by itself define a particular model type and structure, and the application of the method provides parameter values for this model. Economic-valuation techniques (Birol et al. 2007) are an illustrative example.

2. "Model" is part of "method." A research method may involve the use of existing models as a tool, for example a hydrological model used for simulation and impact assessment (Bots and van Daalen 2008, Bots et al. 2010), or a role-playing game used for virtual testing (Kuper et al. 2009) or as an advanced technique for collective interviewing (Bousquet et al. 2002).

3. "Model" equals "result." A research method may aim to produce a model as a representation of the system under study. Such models may be qualitative, such as 
Fig. 1. Scientific research linked to a policy context.

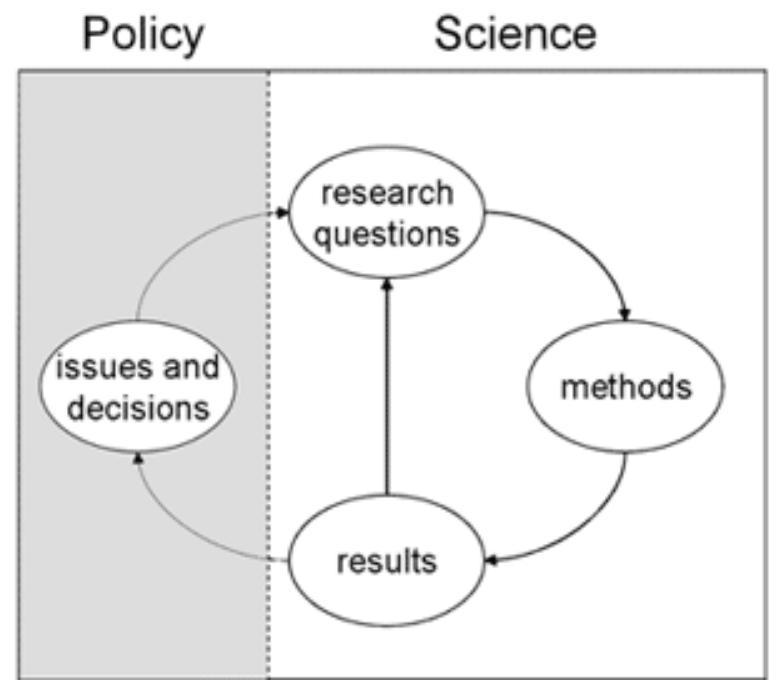

causal diagrams, or quantitative, such as with the use of spreadsheets.

4. "Model"is part of "result." A research method may comprise model development and use; for example, when a model is developed and subsequently used for impact assessment, or when a multi-criteria assessment model is constructed and then used to rank alternatives, such as the tool AquaDT developed in AquaStress (Manez Costa et al. 2007).

We ground this conceptualization of the role of models in research on "actor-network theory." This theory considers that objects and things from the natural and the material world, "non humans," take a specific place within social networks (Callon et al. 1986, Latour 2005): people interact among themselves and with these objects. In this trend, Suchman et al. (2002) focus on the roles of prototypes in the interactions between designers and users in the conception process of photocopiers. In the same way, we consider that models have some form of agency in the research process. Models influence the formulation of research questions, guide the application of methods, and produce results. Models act as intermediary or boundary objects (Star and Griesemer 1989, Vinck 1999) that, once stabilized and proposed to individuals other than their designers, provide new information to these individuals according to their own viewpoints and interests. With several authors, we consider the mediating effect of models when they are used in a collective process (Bousquet et al. 1999, van Paassen 2004). Therefore, we consider models as a special category of "actor" in a participatory research process. They constitute specific nodes in the sociotechnical network that underlies the process, at the same level as various categories of human actors.

We link our model of scientific research to actors and information by conceptualizing a participatory research process as a sequence of information flows in a network of four categories of nodes, where each node represents a category of actors, labeled:

- $\quad S$ (stakeholder): all people who are concerned in their daily life by the policy issue at hand;

- $\quad P$ (policy maker): all people who make decisions concerning the policy issue at hand, regardless of the scale of the issue. Thus, a farmer might be a policy maker within his farm;

- $\quad R$ (researcher): all people who seek knowledge about the system using methods 
Fig. 2. A representation of flows at the policy-science interface.

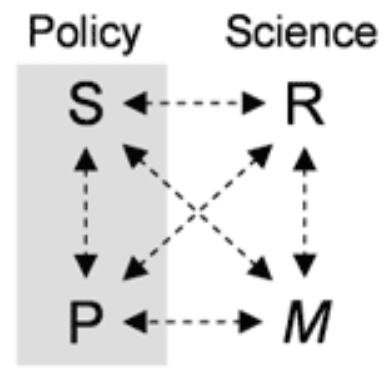

Legend:

$\mathrm{S}$ stakeholders
$\mathrm{P}$ policymakers
$\mathrm{R}$ researchers
$M$ models

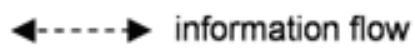

that meet the scientific standards of their discipline; and

- $\quad M$ (model): any kind of representation of the system that is investigated. A model can be formatted information, as well as an information processor that transforms input information into output information using knowledge that is represented in the model as algorithms.

As depicted in Fig. 2, the stakeholder and policymaker categories are associated with the policy context, and the researcher and model categories are associated with the science context. In real life, individuals may belong to more than one category. The categories denote roles, rather than disjoint sets. In fact, policy makers are usually stakeholders in the sense that they are concerned by the policy issue at hand.

The information that flows between these nodes may be of various kinds. For example, stakeholders may provide local knowledge about the natural resource, researchers may provide information on specific methods and the overall research design, models may produce the results of analyses, and policy makers may give feedback on how these results are used in decision making. The control over the information flow is conceptualized as the capacity of each node to "filter" and "transform" the information it possesses (possibly obtained from other actors) before sending it to the following node. This kind of filtering is close to what is described for the constitution of advocacy coalition groups: existing sets of beliefs of any participant filter what is learned (Sabatier and Jenkins-Smith 1999, Weaver and Moore 2004). This occurs even in fully transparent settings.

This is a significantly different way of conceptualizing power, related to our focus on participatory research. More usual in participatory approaches is to focus on the dichotomy between the policy maker and stakeholder that underlies the hierarchy of participation levels proposed first by Arnstein (1969), with a focus on power issues (van Asselt et al. 2001, Mostert 2006). Whereas these authors focus on what "participation" means for policy decision making in terms of political theory (Fung 2006), we focus on the acquisition, transformation, and dissemination of knowledge throughout the participatory process. Thus, we do not want to leave implicit the influence of researchers who have, and may claim monopoly of, "expert" knowledge on specific content and scientific modeling skills (Daniell et al. 2006).

The concepts presented in this section constitute the "building blocks" of our analytic framework. Next, we show the structure of this framework and the kind of results that can be obtained by applying it to characterize differences in implementations of participatory research for natural resource management. 
Fig. 3. Overview of the framework's three facets to explain a participatory research process.

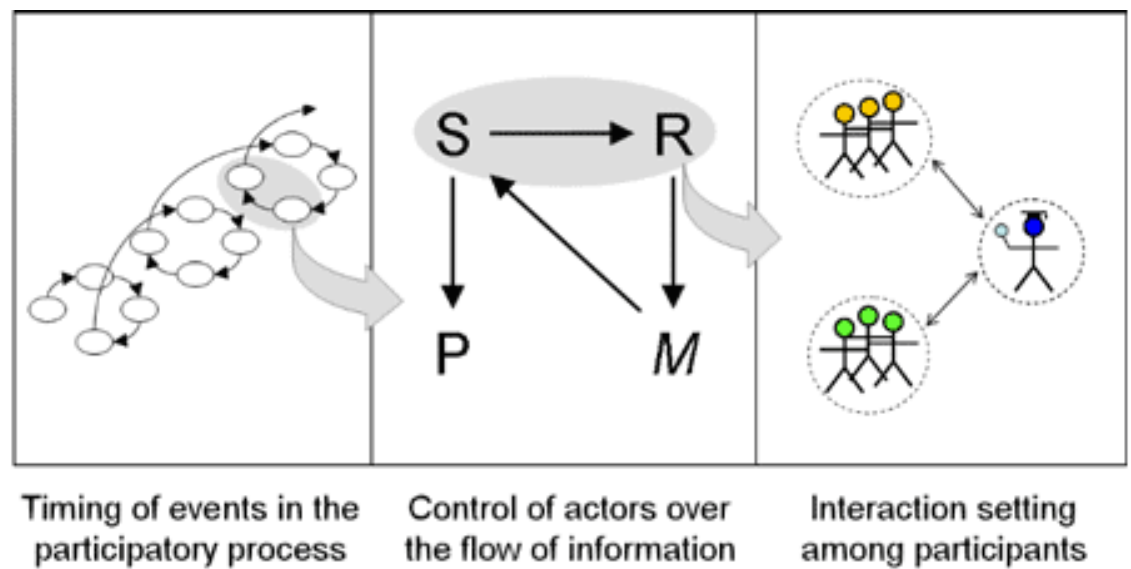

\section{RESULTS}

A participatory research process is seen as a sequence of cycles like the one in Fig. 1. For the purpose of clarifying "participation" in this process, we structure our framework as a triptych with three panels (Fig. 3), where each panel corresponds to one of the three facets we address.

The central panel addresses the dynamics of the process on a very short time scale: one cycle at most, but more likely a single step such as formulating a research question, choosing a method, and applying it. In some cases, these activities may actually constitute several steps. This panel provides the means for one particular step to make explicit who is expected to contribute information, and by whom this will (eventually) be used. This aids participants' understanding of what will be done with their inputs, as well as how their views will be taken into account.

The left hand panel "zooms out" on these dynamics as it addresses the evolution in the structure and control of these information flows over time. It provides the means of making explicit how the organization of the flows differ from one step to the next, and from one cycle to the next, because of differences in the objectives of a step, changes in the issues at stake, or changes in the population of participants. This helps participants understand where in the process their inputs are really expected, and at which points they are involved in framing the research.
The right hand panel "zooms in" on these dynamics, as it addresses the interactive setting for each step and the complexity of social relationships (Eversole 2003). It provides the means of making explicit, down to the level of individuals, who will interact with whom and in what kind of settings, e.g., bilaterally or in open forum, face-to-face or through a mediator. This helps participants to understand the social situations in which they will find themselves when they engage in the process.

\section{Clarifying Participants' Control over Information Flow}

Figure 2 shows information flows as they are planned, with the assumption that they are deliberate and undistorted. An arrow denotes that the actor at the tail generates new knowledge (possibly using information received from other actors), and communicates this effectively (but possibly selectively, emphasizing how it is to be interpreted) to the actor at the head of the arrow. Figure 2 expands the classical bipolar view on participatory processes to a four-pole view. This allows each relation between two nodes, $x$ and $y$, to be taken into account, as well as $x$ 's expectations of the relations that $y$ will have with the other nodes, such as $z$. This entails two dimensions of actor involvement: (1) involvement in generating new knowledge (the immediate flow $x \rightarrow y$ ); and (2) involvement in controlling the spread and use of this new knowledge (future flows $y \rightarrow z$ ). These two dimensions echo the right and left side of Fig. 1. 
Although they are obviously related, it is useful to consider them separately as both provide power and knowledge, either within the research process, or in the social-ecological system in which the research process takes place.

Figure 4 describes these two dimensions of involvement in participatory research, with six examples of flow patterns observed in case studies from NeWater and AquaStress:

1. Information on research outcomes and no control over model use (cf. AquaStress: the Przemska river catchment, Poland);

2. Consultation and no control over model use (cf. NeWater: the Guadiana basin, Portugal).

3. Dialog with researchers and no control over model use (cf. NeWater: the Tisza basin, between Hungary and the Ukraine).

4. Co-building of a model and no control over model use (cf. NeWater: Orange river basin, South Africa, Lesotho, Namibia and Botswana).

5. Dialog with researchers and control over model use (cf. AquaStress: the Vecht catchment, the Netherlands).

6. Co-building of a model and control over model use (cf. AquaStress: the Tadla irrigation scheme, Morocco).

The patterns in Fig. 4 are examples; we do not aim to provide a comprehensive set of categories of flow patterns. Moreover, Fig. 4 displays ideal types of flow patterns. For the sake of clarity, we represent the use of $M$ by either $P$ or $S$ as direct, and not mediated by $R$, even though when a model is made available to them, such mediation often occurs. For the same reason, we draw $(S+) R \rightarrow M$ as a single arrow, whereas in practice there will be numerous flows between (stakeholders plus) researchers and $M$ as they develop the model. The arrows from $M$ to other actors mark the transition from model development to model use.

The degree to which stakeholders can contribute substantive information to the process (the vertical dimension in Fig. 4) is similar to moving upward on Arnstein's ladder of participation (Arnstein 1969):
1. "Information level" means that stakeholders are informed that knowledge about them will be used in the policy process.

2. "Consultation level" implies active involvement of stakeholders in providing relevant information to the researchers. Some knowledge-elicitation techniques, such as the Bayesian belief networks used in the Guadiana (Martínez-Santos et al. 2007), tend to fall in this category. Researchers may filter the information provided by stakeholders, translating this information into pieces of knowledge for the model according to their own pre-existing sets of knowledge and beliefs.

3. "Dialog level" implies iterative and genuinely interactive processes between $S$ and $R$. Researchers still translate stakeholder inputs into $M$, but there is feedback about these developments to $S$, and thus discussion about $M$. Convergence of the discussion remains with $R$, as they make the final modeling decisions. Most group modelbuilding experiments, such as those with flight simulators in the Tisza basin (Haase and Bohn 2007), fall into this category. Stakeholders increase their influence on the framing of the model, as well as on the whole research process, because of better ex ante assessment of the scope of simulations to be examined.

4. "Co-design level" means that the design and/ or implementation of $M$ are joint activities between $R$ and $S$. Co-design workshops and joint application development fall into this category, provided that there is genuinely no translation of $S$ 's inputs by $R$. Techniques originating from artificial intelligence and knowledge engineering, such as knowledge elicitation tools (KnETs; Bharwani 2006), aim to reach this level, either through the implementation of virtual agents that are the extension of stakeholders, or by constraining the interactions among participants through a computer network. This involvement increases the fidelity of the model to match stakeholders' viewpoints and behavioral patterns. However, the protocol for these interactions plays a framing role. If such a framing phase is not defined with $S$, as in some KnETs implementations, then the 
Fig. 4. Categories of participatory research process according to flows of information.

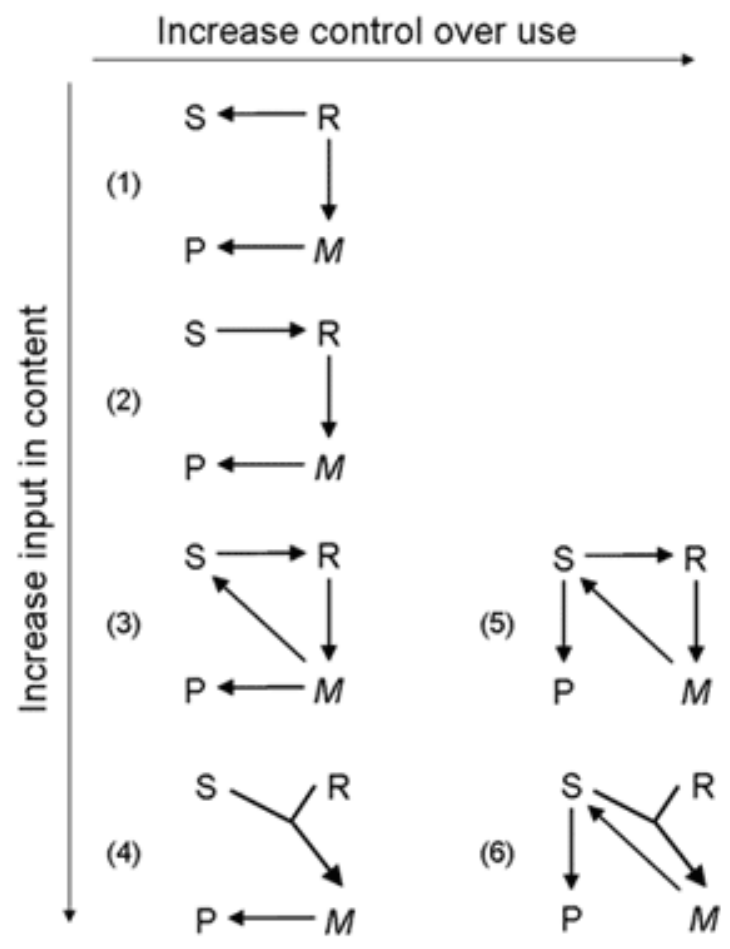

technology facilitates the information flow $S$ $\rightarrow M$, but may deny $S$ the possibility to select much of the information delivered and the format of this information. $S$ 's overall input in the whole participatory research process is thus reduced. This raises the issue of the timing of involvement of participants in the whole process, on top of their level of involvement. We tackle this issue in the second facet of our framework.

The degree to which stakeholders have control over the use of the model (the horizontal dimension of Fig. 4) relates to what happens with $M$, regardless of how it was produced. The first column shows situations in which the model is created and made available together with its outputs to members of $P$, who can then use them. This is the most common pattern. The second column shows situations in which $S$ takes control over the spread and use of $M$, that is, who might use it, within which conditions, and what value may be attached to its outputs. In other words, stakeholders can decide what they believe to be the legitimate use of the research outcomes, and act as filter between models and policy makers. This happens in some stages of the Iskar case study described below. This appropriation requires agreement between researchers and stakeholders about the suitability of a model for various uses (cf. Bots et al. 2010).

\section{Clarifying the Timing of Participatory Events}

We now switch to a dynamic point of view, and consider the possibility of changing the mode of control over information flows in the course of the process (Stringer et al. 2006, Stirling 2008). Our aim is to clarify how the capacity for framing (influencing issues, questions, and methods, for example) is distributed among the actors in the different stages of a participatory research process, where "stage" denotes one or several steps in Fig. 3 , defined by its focus on a very specific objective within the whole process. The number and sequence of stages may vary from case to case. 
We make explicit the evolution of potential participants' control in the process by tracking the flow of information. As can be seen in the example in Fig. 5, the flows of information within the steps of a given stage, as represented in the previous facet, are aggregated. In each stage, there is at least one vertical arrow between two actor categories, $x$ and $y$, and this arrow is a synthesis of the flow of information between $x$ and $y$ during a stage. Doubleheaded arrows denote that the flow of information between $x$ and $y$ is balanced in the sense that they contribute equally to the knowledge produced. The horizontal arrows denote that knowledge produced in one stage is used to inform the next stage, through one or more participants. Each participant may filter this information differently during the transfers.

Figure 5 shows the sequence of interactions in Bulgaria's Iskar basin, one case study of the AquaStress project. The arrows were drawn by the first author of this article while discussing them with one of the most involved researchers in that case study. Therefore, the diagram in Fig. 5 is an ex post analysis, but we emphasize that such a representation of the process can also be made and presented, or even developed in discussion with participants, ex ante. Fig. 5 is provided as an example, and the following points explain how it should be read:

- The parallel vertical flows at the beginning of the diagram (stages "stakeholder analysis" to "research-question elaboration") represent a situation in which members of $S, P$, and some Bulgarian members of $R$ interactively elaborated their own understanding of the "state-of-the-art." It reflects that these participants' involvement in the stakeholder analysis, and their understanding of the "state-of-the-art," developed with existing models known by $P$ and $S$ in mind, then framed their definition of their priority research questions for the region. These stages were predominantly controlled by the members of $R$. Meanwhile, the non-Bulgarian researchers, having initiated a separate research process, led their own "state-of-theart" definition. Participants collectively $(S, P$, and $R$ ) decided on research questions of mutual interest to pursue.

- The stage "value elicitation and vision building" was led by $R$ in two concurrent processes: one with $S$, and one with $P$ that relied on joint design and then use of a model, followed by further dialog toward vision building. The action model design stage was also led by $R$ in two concurrent processes, interacting with $P$ and $S$ separately, but with almost the same level of involvement of $P$ and $S$, the difference being that $P$ was consulted by $R$ when defining the interview questions.

- The subsequent stages are all organized around the model that thus serves as the "backbone" of the tail of the process.

This specification of the sequence of interactions allows an analysis of the distribution of influence. Some stages provide more framing power than others. In this Bulgarian case, we see that an important framing role is maintained by the researchers who keep the leadership on implementing the process and, in particular, in deciding what methods are to be used for the model building. We can also see that considerable framing power has been allocated to stakeholders and policy makers in the initial process stages, including the elaboration of the research question. In the middle of the process, policy makers, through the researchers, gain more knowledge about the stakeholders. If stakeholders had expected to retain more control over their contributions, they might have felt trapped. In contrast, if they had expected opportunities to exchange with policy makers, as was publicized as an objective of the participatory process, they would have appreciated the final stages of the process.

We now take a more general look at the timing of stakeholder involvement in relation to its potential to frame the research process and outcome. Although our example shows that some stages may proceed concurrently, participatory research can be seen as a sequential decision process. The theory of sequential decision making shows that initial decisions can be more consequential than envisaged because they constrain the options for later decisions (Henry 1974, Richard and Trometter 2001). This is an important issue to consider. Participants should realize that when they are involved in the preliminary stages, their choices may frame the process, as well as their capacity to influence it. Such irreversibility will occur, for example, when they shed light on issues that are important to them, or ensure that issues of a too personally sensitive a nature are left out. Even when they can co-decide on the next stages, the stages 
Fig. 5. Flow of interactions with diversity of involvement from each category on the AquaStress Bulgarian case study.

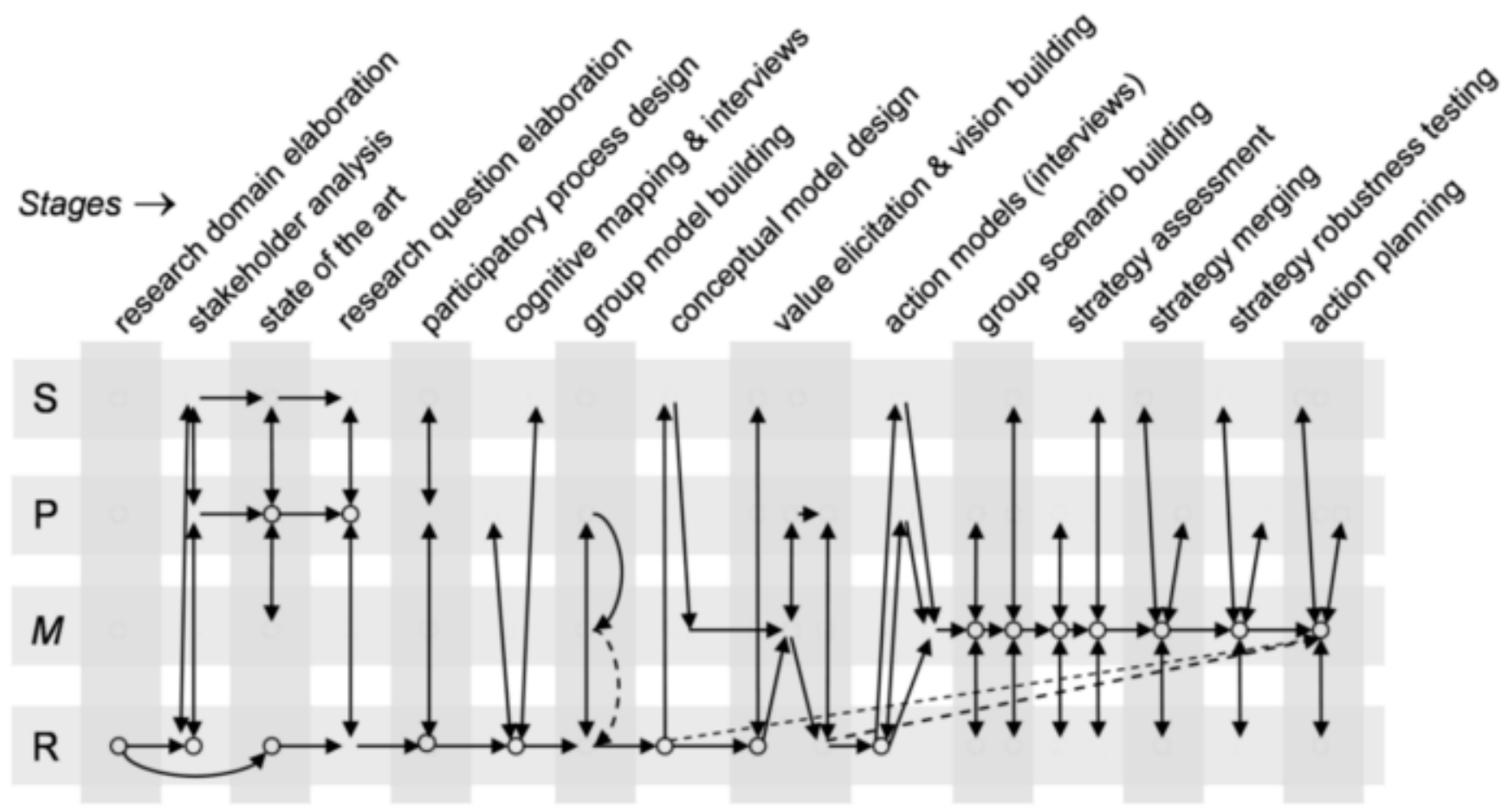

$\uparrow$ Actor categories: $\underline{\text { Stakeholder, }}$ Policy maker, $\underline{\text { Model, }}$ Researcher

denotes which actor category initiates / leads the interaction

already implemented (e.g., participant selection, or choice of simulation scenarios) are likely to generate irreversibilities that limit the introduction of some new sets of research questions raised by newly entering participants, for example, and the scope of the outcomes that can be reached with the selected scenarios.

Some stages are more consequential than others. Conceptual-model design, for example, constitutes a landmark in the process, as it is the crystallization of viewpoints that serves as a reference for further stages. Validation is the stage where stakeholders will have the opportunity to check the effectiveness of the computer model in correctly representing behaviors and processes of interest, as well as on its adequacy to deal with their priority issues. Discussion of results may also constitute a framing phase depending on the purpose of the discussion. If dimensions of discussion are to be defined and the model is open to be modified, there could be some space made for participants to (re-) -orientate the modeling process. Otherwise, if the discussion of results aims to choose from a few scenarios, for example, the choice is very narrow and could be manipulated by the people leading it; often researchers in cases of participatory research.

In the other stages of a research process, the influence of stakeholder involvement on the overall process is weaker. When stakeholders are involved in data collection, or calibration and verification of a computer model, their role tends to be that of an informant. Their involvement is framed by the format of the information that is expected, and by the parts of the model that are to be calibrated. There may be room for some process adaptations to raise the level of participation, but only within a limited scope. 
The implementation of a model can (often silently) empower participants. However, the general purpose of involving stakeholders in this technical activity is typically to raise their literacy in, and knowledge of, this stage, as well as to raise the probability of their deep understanding of the model. The simulation stage then provides information to stakeholders on sets of model results. This technical stage of running simulations is related to a number of strategic choices, including the design of scenarios and indicators to track the simulation progress. Involvement of stakeholders in these technical stages can potentially be made more relevant by using methods such as roleplaying games, that may increase their internal knowledge of the model and understanding of others' perspectives.

\section{Clarifying the Setting in which Participants Exchange Information}

The third facet addressed by our framework is the setting in which participant interactions take place. We advocate clarifying this setting for each stage of the process by opening each of the arrows in the diagrams, with their associated nodes, that were developed for the two previous facets. This means that it should be clear which individuals participate in what role, as it frequently occurs that individuals "wear several hats" and that this poses a problem (Innes and Booher 1999). It should also be clear who will interact with whom, and how. This interaction setting is important because it might influence: (1) the comfort of participants; and (2) the outcomes of the research process, including the knowledge produced.

When researchers organize the process, they may bring into the same arena different groups of people who do not feel comfortable with each others' presence. Martin and Sherington (1997) describe how they had to reorganize the group setting for a participatory process in Uganda because women felt inhibited by the presence of men in the same group. In this example, if researchers had brought together men and women in a joint workshop, these people might have felt trapped if they had not been told in advance that such a meeting would take place. Likewise, participants who understand participation as a way to learn from others, might have been disappointed if not told in advance about the segregated setting. As pointed out by several authors, the structure of interaction co-determines the potential social learning (Pahl-Wostl and Hare 2004, Bots and van Daalen 2008, Pahl-Wostl et al. 2008). The more diverse and unusual the interactions that take place in the participatory process, the more likely it is that participants will learn and build new knowledge during the interactions.

Bots and van Daalen (2008) distinguish three ways in which stakeholders can be involved in a participatory modeling exercise, which we extrapolate here to participatory research as depicted schematically in Fig. 6: (a) stakeholders are involved individually; (b) stakeholders are involved as a group that is considered as a whole by the researcher, independent of stakeholders' diversity; and (c) stakeholders are involved as a heterogeneous group, meaning that the participants have divergent, and possibly conflicting, interests and problem perceptions, and that the participatory process is organized with subgroups to deal with this heterogeneity.

The dotted lines in Fig. 6 demarcate interaction boundaries between actors, and the arrows denote interaction organized and facilitated by the researcher. Researchers may have methodological reasons for choosing one of these ways. They may, for example, opt for (a) and conduct interviews so as not to let actors influence each other during a data-collection stage; they may prefer (b) and let actors pool their local knowledge concerning a particular model parameter, e.g., rainfall, during a model-calibration stage; or they may prefer (c) to elicit different stakeholder perspectives while developing scenarios, or to study the negotiation behavior of actors during a gaming simulation.

Researchers organizing a participatory process face a trade-off between the aim of fostering emergence of new ideas through mixing heterogeneous participants, and the necessity to deal with bias, inhibition, and frustrations that might be fostered by heterogeneous settings. It is important to make this trade-off explicit, because if the implementation does not match expectations, it can generate disappointment (e.g., "we thought we would meet farmers from other areas"), a feeling of being trapped (e.g., "how dare they ask us these questions while $X$ is here!"), as well as disappointing outcomes in terms of social learning (e.g., "OK, we got the chance to explain our point of view to $X$, but there was no feedback and discussion"). 
Fig. 6. Different ways of involving potentially heterogeneous actors in participatory research.

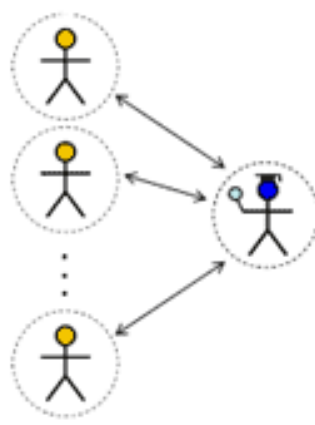

(a)

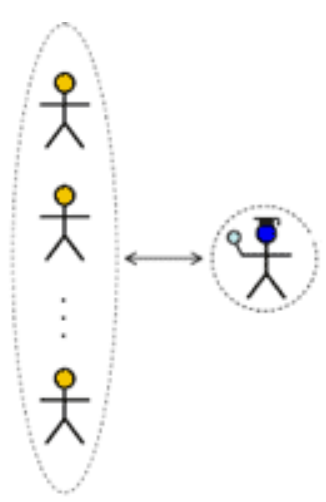

(b)

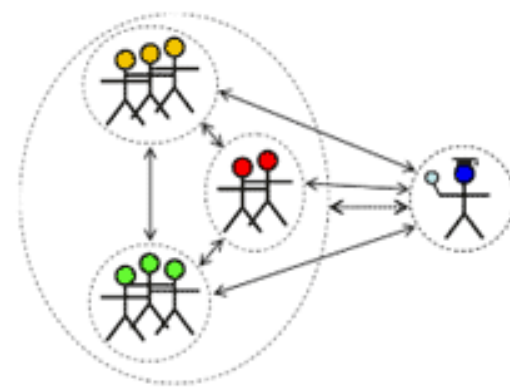

(c)

\section{DISCUSSION}

We have proposed a framework that allows the characterization of participation in research by investigating three facets: control over information flow, evolution of participation modes across research stages, and management of participants' heterogeneity. The initial aim of developing this framework was to prevent participants' disappointment. We first discuss the capacity of the framework to do this. Second, we show that the framework can also be used in the design and monitoring of participatory research processes, enhancing the reflexivity of designers as well as of participants. Finally, we point out some new insights on participatory research that were gained while developing the framework.

\section{Preventing Disappointment}

The alternative implementations of participatory research that can be generated by investigating the three facets of the proposed framework provide a large variety of potential empowerment levels, control over the process, and consequences for participants. For example, participants' expectations may be diverse, with some keen on being involved in decision making, some unwilling to share responsibility for future outcomes, some wishing to prevent the process from coming up with undesirable options, some seeking recognition of their own knowledge, some taking the opportunity to interact with other specific participants, and others being merely curious about what is happening. Considering the potentially large discrepancies between implementation realities and participants' expectations relative to these realities, we explain how the proposed framework can help prevent disappointment.

Disappointment occurs in situations where participants experience unexpected feelings, a lack of pleasure, a lack of control over the process, and/ or some breach of their legitimacy (Zeelenberg et al. 2000). To properly address disappointment, we need to consider two differences that may serve as proxy for assessing disappointment linked to participatory research: (1) the difference between the actual process as it has been perceived (e.g., "it felt like a trial; we were accused of ...") and the process as it had been expected (e.g., "we came to have an open-minded discussion about ..."); and (2) the difference between the actual results (e.g., "we learned nothing new," or "the meeting ended in a stand-off") and the results that were expected to be produced by the process (e.g., "the experts will tell us how ..." or "we believed that a decision would finally be made").

It is important to take in account the process "as perceived" by participants and not "as implemented" by the leaders of the process, because of the possibility of procedural misunderstandings. The 
proposed framework is developed to deal with the first proxy. It addresses three of the four aspects of disappointment mentioned above.

1. Unexpectedness. Providing procedural information and updates when changes occur on each of the three facets of the framework, will decrease the gap between the process as perceived and the process as actually implemented, hence limiting an important source of unexpectedness.

2. Control. Even though explaining the process does not change the control over the process by itself, not giving explanations about the process may induce a feeling of loss of control. If information flows beyond the scope that was initially understood by participants (e.g., policy makers obtain the fine-grain model of water use that researchers co-constructed with stakeholders who expected that the data on their individual water use would be presented to policy makers only in aggregated form), or if the interaction setting leads some participants into unwanted meetings, participants will have the feeling that someone else has exerted undeclared control over the process, inducing a relative loss of control for them.

3. Legitimacy. The capacity (specified in facets 1 and 2) to control information flows and to control framing in the process is linked to the institutional and technical legitimacy that is granted to them by the leaders of the process. Facet 3 specifies the possibility of participants' access to a given arena, that also reflects a view of participants' legitimacy to access this arena.

The fourth facet, pleasure, is not covered, or is only indirectly addressed through preventing unexpected displeasure in situations of interaction.

A consequence of disappointment is usually nonaction in similar future situations (Zeelenberg et al. 2000), so disappointed participants are likely to decline new opportunities for involvement in similar participatory research processes. The greater the disappointment that is associated with a specific type of implementation of participatory research, the more it will be associated with participatory research as a general category. This decreases the public good that is its reputation as a methodology. Therefore, the likelihood increases that people will refuse to participate in future research processes for the wrong reasons.

\section{Design and Monitoring of Participatory Research Processes}

Our framework is meant to be used for design and monitoring. We first return to the issue of the control over the process that is entrusted to participants, and its publicity. Second, we explain how this framework can be used to organize the implementation and tracking of the participatory research process. Third, we explain what such explicit ex ante planning can mean for a process that should still be adaptive.

The framework provides support to reach mutual agreements with participants on a participatory research process. Such an agreement can specify the sequence of stages, and for each stage, who has control over information and what kind of interactions among participants take place. Thus, it defines a set of shared "rules of practice" for participation. As participatory research processes often need to adapt to findings and changing circumstances, such an agreement should not freeze the process design. Therefore, it should also set the meta-rules on how the three facets will be set and revised as the process unfolds. Processes may, for example, feature "participatory process design" stages like the one presented in Fig. 5. By communicating the rules for these stages, participants will know beforehand when and to what extent they may change the course of the process, and their role in it.

Delegation of control to participants is also important for the quality of the research process itself. Most of the case studies that inspired the proposed framework showed that stakeholders will hold back information until they are sure that what they say will not be used against them afterward. However, this behavior of controlling what is said will not be the same for all participants. If this is not well managed through the setting of interactions, a participatory research process might lead to increased inequality among people. For example, some marginalized groups may reveal their interests or objectives, whereas groups with more power may be more guarded and take strategic advantage of the information provided by others. 
The concepts and categories we have proposed may also support the participatory implementation of participatory research processes. Before each stage, there should be at least information on further procedural definition (Elwood 2007), including control over information, its place in the whole process, and interactions with other participants. These dimensions then provide a frame for tracking what is being done, such as in a logbook, so that ex post assessment or comparison of the participatory process is possible, beyond only the process outcomes.

Finally, we want to once again emphasize that our framework is only a means for clarifying what is meant by "participation" during the design and implementation phases of participatory research. Clarity will enable participants to better assess the consequences of a particular design (e.g., "in this setup I can influence the research to have my concerns taken into account, but this may reveal a lot about myself, and I have no control over how this information will be presented to other actors") and then make a trade-off. What is "better" depends on an actor's position and context. Therefore, we want to avoid any suggestion that patterns higher on the two dimensions in Fig. 4 would be superior. We also want to avoid the impression that by urging to make explicit ex ante the overall process (the left panel in Fig. 4), we advocate a preset and rigid design. As a case study in Pakistan (Butz 2008) illustrates, it is not possible to conduct a participatory process with everything planned out beforehand, as this would have precluded the inputs from participants that were aimed for. Clarity and flexibility do not exclude each other. Showing the planned sequence of the interactions provides good support for assessing whether all intended flows will be achieved with appropriate controls. However, this sequence should be considered as indicative, and be presented together with procedures for making modifications.

\section{CONCLUSIONS AND SPECULATION}

We have argued here that the possibility of disappointing participants in participatory research constitutes a risk for the whole participatory research community, and that this risk can be mitigated by better articulating the differences in design and implementation that give rise to the large diversity of participatory research processes. For that purpose, we have proposed a conceptual framework to support ex ante the explanation of the participatory research process to would-be participants. This framework is based on a very generic view of scientific-knowledge production in interaction with policy making. It provides concepts and relations for clarifying three facets of a participatory research process: (1) the flow of information and the control over this flow; (2) the evolution of planned involvement across the various stages of the participatory research process; and (3) the settings of the interactions to be encountered. This framework is prescriptive only from a procedural point of view. The three facets of the process should be made explicit and clear to all participants. The framework does not prescribe any particular design or implementation choices concerning these three facets. Such decisions should be adapted to the local context.

Even though we developed the framework by reflecting ex post on recent experiences, we see the framework's future role predominantly as a tool to be used ex ante and throughout a participatory process from the inception stage to its end. Its use should lead to more deliberate acceptance to participate all along the process. By stating at the outset the level of involvement, the sequence, and the format of interactions, and re-stating these elements during the course of the process, we expect that participants will make better informed decisions about whether or not to participate. Its use should also lead to more structured debriefings. Initial information constitutes a benchmark that can be used to assess the actual process ex post, hence leading participants to build sound representations of participatory processes for themselves.

We consider this framework as a basis for organizing the communication of an upcoming process to would-be participants. It still needs to be developed into practical guidelines for researchers who plan to engage in a participatory research process. Such guidelines and their implementation in the field could be shaped using the following protocol:

1. The researchers engaging a participatory research process should make clear to themselves what kind of participatory research they want to undertake, and write this down in the form of a plan. This plan should address all three facets of the proposed framework. The researchers should adapt this plan throughout the process, which means that they should be ready to rethink at any stage the stages ahead. The plan is a picture 
of the process as it is intended at a given moment; it may be updated to accommodate new views.

2. The researchers should explain and discuss the proposed process with the people they wish to involve in the research, opening the door for modifications. In this discussion, they should also address rules and procedures for updating the plan. This type of "procedural communication" is already practiced, although it is often based on ethics regulations (e.g., Australian Government 2007), but its scope and time horizon differ. Daniels et al. (2005), for example, informed participants at the beginning of focus-group sessions that their participation is voluntary, that the tape recordings of their discussions will remain confidential, and that findings will be anonymized. When organizing citizens' juries, Iredale and Longley (2000) briefed the experts they wanted to involve as witnesses a few weeks ahead of the event, explaining in individual meetings the nature of their participation. In their efforts to sensitize stakeholders to the characteristics and potential benefits of a particular approach to participatory research called "companion modeling," Etienne et al. (2008) made leading stakeholders discuss the research protocol before its implementation. This preinformation took place in outreach meetings in which earlier applications of the companion modeling approach were presented as examples (Barreteau et al. 2010). Such practices of "procedural communication" which are common, but rarely documented in the peer-reviewed literature, provide a good starting point for the development of methods for explaining to stakeholders how a participatory process will take place. We advocate that, unlike in the examples provided, this explanation should take place well ahead of any event, and target all the people researchers aim to involve. We suggest communicating the three facets of our framework in the following order: (1) Using illustrative stories as examples, explain that there are different possible levels of involvement and control (see Fig. 4), and that these may vary from stage to stage in the process. (2) Explain the planned sequence of stages, their specific purposes, and the proposed levels of involvement and control.
(3) Explain the structure of interactions, along this sequence, making clear who will have the opportunity to talk to whom. The level and form of communication should be carefully adapted to the stakeholders and context. The symbolic representation presented in the framework is a conceptual guide for researchers. The use of more understandable language and other pictorial representations is likely to be essential for effective communication with potential research participants.

3. The researchers should start to track the process according to the same framework to make explicit the gaps between their initial plan and the actual implementation. Specific logbooks for participatory research should be developed and modeled after the ethnographers' diaries or the experimenters' lab journal. Such a logbook would increase the participants' capacity, irrespective of their roles, for reflection and learning. These ideas are presently explored in practice (Etienne 2009).

4. Each time the plan is to be updated, the researchers should redo points 1 and 2. For example, Barnaud (2008) followed this practice in her implementation of the companion-modeling approach in Thailand by continuously sensitizing participants to this approach using stories and photos of an earlier implementation as an example.

5. After each interactive stage in the process, the researchers should debrief the method with participants to allow revisions and management of participants' expectations, using the framework as a guideline. As described in the literature on debriefing gaming simulations, after every participatory event the researchers should create an opportunity for participants to express their feelings about this event (Kriz 2008). This typically takes the form of an open-group discussion about what happened during a participatory event, prompted by questions such as: "how did you feel during the session?," "do you wish to express some specific messages to your fellow participants?," or "when did you not feel at ease and why?". Although it is more productive to hold a group discussion, the researcher leading the participatory research may prefer individual 
interviews or written questionnaires with the same questions.

In summary, we consider this proposed framework to be a basis for facilitating and setting a standard for good practices in participatory research. We believe that this is important not only from an ethical perspective in terms of demonstrating respect toward participants, but also from a utilitarian perspective. We should cherish and cautiously manage the stakeholders' willingness to participate as a public good for the participatory research community.

Responses to this article can be read online at:

http://www.ecologyandsociety.org/voll5/iss2/artl/responses/

\section{Acknowledgments:}

This research is part of the Integrated Projects NeWater and AquaStress financed by the Sixth EU Framework Programme for Research and Technological Development (FP6), with contract numbers 511231-2 and 511179(GOCE). The second author's contribution was co-funded by the Next Generation Infrastructures foundation (project "Harnessing Multi-Actor System Complexity"). The authors are thankful to Audrey Richard for inspiring discussions regarding this paper.

\section{LITERATURE CITED}

Arnstein, S. 1969. A ladder of citizen participation. Journal of the American Planning Association 35 (4):216-224.

Australian Government. 2007. National statement on ethical conduct in human research. National Health and Medical Research Council, Australian Research Council, and Australian Vice-Chancellors' Committee, Canberra, Australia. [online] URL: htt p://www.nhmrc.gov.au/publications/synopses/e72syn. $\underline{\mathrm{htm}}$

Barbier, R. 2005. Quand le public prend ses distances avec la participation. Natures Sciences Sociétés 13:258-265.
Barnaud, C. 2008. Equité, jeux de pouvoir et légitimité: les dilemmes d'une gestion concertée des ressources renouvelables. Paris X, Nanterre, France.

Barnett, C. 2004. Pro-poor dissemination: increasing the impact of research. Development in Practice 14(3):432-439.

Barreteau, O., P. W. G. Bots, K. A. Daniell, M. Etienne, P. Perez, C. Barnaud, D. Bazile, N. Becu, J.-C. Castella, W. Daré, and G. Trebuil. 2010. Participatory approaches and simulation of social complexity. In B. Edmonds, and S. Moss, editors. Simulating social complexity: a handbook. Springer, Berlin, Germany, in press.

Barreteau, O., and Y. von Korff. 2007. Synthesis report on mid-term progress with stakeholder processes in case studies. Report to NeWater. D 3.1.3. Cemagref, Montpellier, France. [online] URL: http://www.newater.uos.de/intern/sendfile.php? $\underline{\mathrm{id}=873}$

Beierle, T. C., and J. Cayford. 2002. Democracy in practice: public participation in environmental decisions. Resources for the Future, Washington, D.C., USA.

Bharwani, S. 2006. Understanding complex behavior and decision making using ethnographic knowledge elicitation tools (KnETs). Social Science Computer Review 24(1):78-105.

Biggs, S. D. 1989. Resource-poor farmer participation in research: a synthesis of experiences from national agricultural research systems. OFCOR, comparative Study No. 3. International Service for National Agricultural Research, The Hague, The Netherlands.

Birol, E., P. Koundouri, and Y. Kountouris. 2007. Using economic valuation techniques to inform water resources management in the southern European, Mediterranean and developing countries: a survey and critical appraisal of available techniques. Pages 135-155 in P. Koundouri, editor. Coping with water deficiency. Springer, Berlin, Germany.

Blumenthal, D., and J.-L. Jannink. 2000. A classification of collaborative management methods. Conservation Ecology 4(2): 13. [online] URL: http 
://www.ecologyandsociety.org/vol4/iss2/art13

Bots, P. W. G., and C. E. van Daalen. 2008. Participatory model construction and model use in natural resource management: a framework for reflection. Systemic Practice and Action Research 21(6):381-515.

Bousquet, F., O. Barreteau, P. d'Aquino, M. Etienne, S. Boissau, S. Aubert, C. Le Page, D. Babin, and J.-C. Castella. 2002. Multi-agent systems and role games: an approach for ecosystem co-management. Pages 248-285 in M. Janssen, editor. Complexity and ecosystem management: the theory and practice of multi-agent approaches. Edward Elgar, Cheltenham, UK.

Bousquet, F., O. Barreteau, C. Le Page, C. Mullon, and J. Weber. 1999. An environmental modelling approach: the use of multi-agent simulations. Pages 113-122 in F. Blasco, and A. Weill, editors. Advances in environmental and ecological modelling. Elsevier Science, Paris, France.

Butz, D. 2008. Sidelined by the guidelines: reflections on the limitations of standard informed consent procedures for the conduct of ethical research. ACME: An International E-Journal for Critical Geographies 7(2):239-259.

Callon, M., J. Law, and A. Rip. 1986. Mapping the dynamics of science and technology: sociology of science in the real world. Macmillan, London, UK.

Cleaver, F. 1999. Paradoxes of participation: questioning participatory approaches to development. Journal of International Development 11:597-612.

Cornwall, A., and R. Jewkes. 1995. What is participatory research? Social Science and Medicine 41(12):1667-1676.

d'Aquino, P. 2009. La participation comme élément d'une stratégie globale d'intervention: l'approche « gestion autonome progressive ». Cahiers / Agricultures 8(5):433-440.

Daniell, K.A., N. Ferrand, and A. Tsoukias. 2006. Investigating participatory modelling processes for group decision aiding in water planning and management. Pages 207-210 in S. Seifert, and C.
Weinhardt, editors. Proceedings of the Group Decision and Negotiation (GDN) 2006 International Conference. Universitätsverlag, Karlsruhe, Germany.

Daniels, K., H. van Zyl, M. Clarke, J. Dick, and E. Johansson. 2005. Ear to the ground: listening to farm dwellers talk about the experience of becoming lay health workers. Health Policy 73:92-103.

Driessen, P. P. J., P. Glasbergen, and C. Verdaas. 2001. Interactive policy-making - a model of management for public works. European Journal of Operational Research 128(2):322-337.

Elwood, S. 2007. Negotiating participatory ethics in the midst of institutional ethics. $A C M E$ : $A n$ International E-Journal for Critical Geographies 6 (3):329-338.

Etienne, M., editor. 2009. La modélisation d'accompagnement: une démarche participative en appui au développement durable. Editions Quae, Paris, France.

Etienne, M., M. Bourgeois, and V. Souchère. 2008. Participatory modelling of fire prevention and urbanisation in southern France: from coconstructing to playing with the model. Pages 972 979 in M. Sànchez-Marrè , J. Béjar, J. Comas, A. Rizzoli, and G. Guariso, editors. Proceedings of the Fourth Biennial Conference of the International Environmental Modelling and Software Society (iEMSs). Barcelona, Spain. [online] URL: http://w ww.iemss.org/iemss2008/uploads/Main/S11-07Etienne et al-IEMSS2008.pdf

Eversole, R. 2003. Managing the pitfalls of participatory development: some insight from Australia. World Development 31(5):781-795.

Fischer, G., E. Giaccardi, H. Eden, M. Sugimoti, and Y. Ye. 2005. Beyond binary choices: integrating individual and social creativity. International Journal of Human-Computer Studies 63:482-512.

Forssén, M., and P. Haho. 2001. Participative development and training for business processes in industry: review of 88 simulation games. International Journal of Technology Management 22(1-3):233-262.

Fossey, E., C. Harvey, F. McDermott, and L. Davidson. 2002. Understanding and evaluating 
qualitative research. Australian and New Zealand Journal of Psychiatry 36:717-732

Fung,A. 2006. Varieties of participation in complex governance. Public Administration Review 66 (1):66-75.

Glendinning, A., A. Mahapatra, and C. P. Mitchell. 2001. Modes of communication and effectiveness of agroforestry extension in eastern India. Human Ecology 29(3):283-305.

Goldspink, C. 2002. Methodological implications of complex systems approaches to sociality: simulation as a foundation for knowledge. Journal of Artificial Societies and Social Simulations 5(1):3. [online] URL: http://jasss.soc.surrey.ac.uk/5/1/3.html

Haase, D., and C. Bohn. 2007. Mid-term reporting on progress on the stakeholder processes in the Tisza basin. Report to NeWater. D 3.5.4. Zentrum für Umweltforschung (UFZ), Leipzig, Germany. [online] URL: http://www.newater.uos.de/intern/se ndfile.php?id=486

Hare, M. P., R. A. Letcher, and A. J. Jakeman. 2003. Participatory modelling in natural resource management: a comparison of four case studies. Integrated Assessment 4(2):62-72.

Henry, C. 1974. Investment decisions under uncertainty: the "irreversibility effect." The American Economic Review 64(6):1006-1012.

Heywood, A. 2003. Political ideologies: an introduction. Third edition. Palgrave Macmillan, London, UK.

Innes, J. E., and D. E. Booher. 1999. Consensus building as role playing and bricolage: toward a theory of collaborative planning. Journal of the American Planning Association 65(1):9-26.

Iredale, R., and M. Longley. 2000. Reflections on citizens' juries: the case of the citizens' jury on genetic testing for common disorders. Journal of Consumer Studies and Home Economics 24(1):4147.

Kriz, W. C. 2008. A systemic-constructivist approach to the facilitation and debriefing of simulations and games. Simulation and Gaming
DOI:10.1177/1046878108319867. [online] URL:

http://sag.sagepub.com/cgi/rapidpdf/104687810831 9867v1.pdf

Kujala, S. 2003. User involvement: a review of the benefits and challenges. Behaviour and Information Technology 22(1):1-16.

Kuper, M., M. Dionnet, A. Hammani, Y. Bekkar, P. Garin, and B. Bluemling. 2009. Supporting the shift from state water to community water: lessons from a social learning approach to designing joint irrigation projects in Morocco. Ecology and Society 14(1): 19. [online] URL: http://www.ecologyandso ciety.org/vol14/iss1/art19/

Latour, B. 2005. Reassembling the social: an introduction to Actor-Network-Theory. Oxford University Press, Oxford, UK.

Lewin, K. 1946. Action research and minority problems. Journal of Social Issues 2:34-46.

List, D. 2006. Action research cycles for multiple futures perspectives. Futures 38(6):673-684.

Manez Costa, M., S. Panebianco, and P. Koundouri. 2007. Report on innovative socioeconomic measures and results to adaptive management procedures. Outcome: social multicriteria tool. AquaStress. D2.3-2. Institute of Environmental Systems Research (USF), Osnabrück, Germany. [online] URL: http://www.aquastress.net/share/img deliverables file/181 D2.3-2.pdf

Martin, A., and J. Sherington. 1997. Participatory research methods-implementation, effectiveness and institutional context. Agricultural Systems 55 (2):195-216.

Martínez-Santos, P., N. Hernández-Mora, and M. R. Llamas. 2007. Guadiana case study: interim stakeholder report. Report to NeWater. D 3.4.4. Universidad Complutense de Madrid, Spain. [online] URL: http://www.newater.uos.de/intern/se ndfile.php?id $=1281$

Miettinen, R., and J. Virkkunen. 2005. Epistemic objects, artefacts and organizational change. Organization 12(3):437-456.

Mostert, E. 2006. Participation for sustainable water management. Pages 153-176 in Giupponi, C., 
A. J. Jakeman, D. Karssenberg, and M. P. Hare, editors. Sustainable management of water resources. Edward Elgar, Cheltenham, UK.

Ostrom, E., R. Gardner, and J. Walker. 1994. Rules, games and common-pool resources. The University of Michigan Press, Ann Arbor, Michigan, USA.

Pahl-Wostl, C., and M. Hare. 2004. Processes of social learning in integrated resources management. Journal of Community and Applied Social Psychology 14:193:206.

Pahl-Wostl, C., P. Kabat, and J. Möltgen, editors. 2007. Adaptive and integrated water management: coping with complexity and uncertainty. Springer, Berlin, Germany.

Pahl-Wostl, C., E. Mostert, and D. Tàbara. 2008. The growing importance of social learning in water resources management and sustainability science. Ecology and Society 13(1): 24. [online] URL: http: //www.ecologyandsociety.org/vol13/iss1/art24/.

Pereira, A. G., J.-D. Rinaudo, P. Jeffrey, J. Blasques, S. Corral Quintana, N. Courtois, S. Funtowicz, and V. Petit. 2003. ICT tools to support public participation in water resources governance and planning: experiences from the design and testing of a multi-media platform. Journal of EnvironmentalAssessment Policy and Management 5(3):395-420.

Probst, K., and J. Hagmann. 2003. Understanding participatory research in the context of natural resource management-paradigms, approaches and typologies. Agricultural Research and Extension Network (AgREN) Paper No. 130. [online] URL: http://www.odi.org.uk/networks/agren/ papers/agrenpaper 130.pdf.

Richard, A., and M. Trometter. 2001. Les caractéristiques d'une décision séquentielle: effet irréversibilité et endogénéisation de l'environnement Revue Economique 52(3):739-752.

Rowe, G., and L. J. Frewer. 2000. Public participation methods: a framework for evaluation. Science, Technology and Human Values 25(1):329.

Rykiel, E. J. 1996. Testing ecological models: the meaning of validation. Ecological Modelling 90:229-244.

Sabatier, P. A., and H. C. Jenkins-Smith. 1999. The advocacy coalition framework: an assessment. Pages 117-166 in P. A. Sabatier, editor. Theories of the policy process. Westview, Boulder, Colorado, USA.

Star, S. L., and J. R. Griesemer. 1989. Institutional ecology, "translations" and boundary objects: amateurs and professionals in Berleley's Museum of Vertebrate Zoology, 1907-39. Social Studies of Science 19(3):387-420.

Stirling, A. 2008. "Opening up" and "closing down": power, participation, and pluralism in the social appraisal of technology. Science, Technology and Human Values 33(2):262-294.

Stringer, L. C., A. J. Dougill, E. Fraser, K. Hubacek, C. Prell, and M. S. Reed. 2006. Unpacking "participation" in the adaptive management of social-ecological systems: a critical review. Ecology and Society 11(2): 39. [online] URL: http://www.ecologyandsociety.org/vol11/iss2/ art39.

Suchman, L., R. Trigg, and J. Blomberg. 2002. Working artefacts: ethnomethods of the prototype. British Journal of Sociology 53(2):163-179.

van Asselt, M., J. Mellors, N. Rijkens-Klomp, S. Greeuw, K. Molendijk, P. Beers, and P. van Notten. 2001. Building blocks for participation in integrated assessment: a review of participatory methods. ICIS Working Paper I01-E003. International Centre for Integrated Assessment and Sustainable Development (ICIS), Maastricht, The Netherlands.

van den Hove, S. 2000. Participatory approaches to environmental policy-making: the European Commission climate policy process as a case study. Ecological Economics 33(457):472.

van Paassen, A. 2004. Bridging the gap: computer model enhanced learning about natural resource management in Burkina Faso. Tropical Resource Management Papers 49. Wageningen University, Wageningen, Netherlands. [online] URL: http://lib rary.wur.nl/ebooks/1708976.pdf 
Vinck, D. 1999. Les objets intermédiaires dans les réseaux de coopération scientifique. Revue Française de Sociologie 40(2):385-414.

von Korff, Y. 2005. Towards an evaluation method for public participation processes in AquaStress and NeWater: a proposal for both projects. AquaStress and NeWaterinternal working document, Sixth EU Framework Programme. Cemagref, Montpellier, France.

von Korff, Y., and O. Barreteau. 2005. Protocol for tracking the extent and quality of stakeholder involvement (participation) in NeWater case studies. NeWater internal report. Cemagref, Montpellier, France.

Walker, B., S. Carpenter, J. Anderies, N. Abel, G. Cumming, M. Janssen, L. Lebel, J. Norberg, G. D. Peterson, and R. Pritchard. 2002. Resilience management in social-ecological systems: a working hypothesis for a participatory approach. Conservation Ecology 6(1): 14. [online] URL: http ://www.ecologyandsociety.org/vol6/iss1/art14.

Weaver, M., and R. Moore. 2004. Generating and sustaining collaborative decision-making in watershed groups. Sixty-seventh Annual Meeting of the Rural Sociological Society. 12-15 August 2004, Sacramento, California, USA.

Zeelenberg, M., W. W. van Dijk, A. S. R. Manstead, and J. van der Pligt. 2000. On bad decisions and disconfirmed expectancies: the psychology of regret and disappointment. Cognition and Emotion 14(4):521-541. 